\title{
A Arqueologia do Saber: Sobre os "Sistemas de Formação" e os "Sujeitos Falantes" do Século XXI
}

[The Archeology of Knowledge: On the "Systems of Formation" and the "Speaking Subjects" of the 21st Century]

\section{Itamar Soares Veiga ${ }^{\Uparrow}$}

Resumo: Este estudo aprofunda o texto da Arqueologia do saber com o objetivo de estabelecer uma aproximação entre esta obra de Foucault e os sujeitos falantes no século XXI. Este aprofundamento é realizado em duas etapas. Em primeiro lugar, alguns conceitos da arqueologia são destacados, como o de estratégias e o de sistema de formação das práticas discursivas. Em segundo lugar, os sistemas de formação são abordados enquanto sistemas de dispersão e aproximados com as práticas comunicativas atuais. A análise acompanha o texto de Foucault juntamente com alguns principais interpretes e acrescenta, por fim, um diálogo com as posições de Byung-Chul Han a respeito de um panóptico digital aperspectivístico. A conclusão reforça que o conceito de sistema de formação de práticas discursivas se constitui um recurso importante para interpretar o mundo atual.

Palavras-chave: arqueologia, sistema de formação, estratégias, unidades de discurso.

Abstract: This study deepens the text of Archeology of knowledge with the aim of establishing an approximation between this work of Foucault and the speaking subjects in the 21 st century. This deepening is done in two stages. In the first place, some concepts of archeology are highlighted, such as that of strategies and the system of formation of discursive practices. Secondly, systems of formation are approached as dispersion systems and approximated with current communicative practices. The analysis accompanies Foucault's text jointly with some leading interpreters and adds, finally, a dialogue with Byung-Chul Han's positions on an aperspectivistic digital panopticon. The conclusion reinforces that the concept of the system of formation of discursive practices constitutes an important resource to interpret the present world.

Keywords: archeology, system of formation, strategies, units of discourse.

${ }^{*}$ Professor do curso de filosofia e do Programa de Pós-graduação da Universidade de Caxias do Sul (UCS). Doutor em filosofia pela Pontifícia Universidade Católica do Rio Grande do Sul (PUC-RS).

E-mail: inpesquisa@yahoo.com.br. ORCID: https://orcid.org/0000-0003-4275-0486. 
Uma das formas de aproximar a reflexão de Foucault aos dias atuais é percorrer as suas obras, incluindo todos os seus cursos, e estabelecer analogias com as relações de poder e de saber existentes na atualidade. Isto parece evidente, mas não é algo simples de ser realizado. Parte da explicação desta dificuldade reside na escolha de um eixo geral suficientemente profundo para dar conta das diferentes vias de análise de Foucault, suas fases e temas. E, no outro lado de uma possível analogia, estão os diferentes cenários atuais com suas específicas complexidades. Isto justifica delimitar um escopo factível com condições de contribuir para as pesquisa sobre este autor.

Nesta delimitação, este artigo trabalha com a seguinte hipótese geral: a leitura do texto de Arqueologia do saber provê um recurso para a interpretação da realidade atual. Este recurso é alcançado por meio de uma apropriação das performances enunciativas provenientes das unidades de discurso, as quais contêm sistemas de formação das práticas discursivas, sistemas de dispersão e, também, funções enunciativas. Estas funções enunciativas revelam domínios de saber dentro da efetividade do mundo. A explicitação desta efetividade manifesta as positividades que são as condições das próprias funções enunciativas. Neste conjunto, o sistema de formação das práticas discursivas é aprofundado para interpretar a época atual. Isto implica considerar a possibilidade da mediação tecnológica entre os sujeitos em suas práticas discursivas. Assim, na expressão "época atual", nós queremos referir o século XXI e a situação das relações humanas imersas em conexões digitais e mídias, o que é exemplificado pelo uso de redes sociais. Isto significa que, dentro do escopo desta hipótese, o "sujeito falante" da Arqueologia do saber deverá ser "projetado" em um novo âmbito: o âmbito da "prática discursiva" no uso disseminado da informática.

A hipótese acima será orientada pelo aprofundamento desta pergunta: os sistemas de formação das práticas discursivas, mencionados na Arqueologia do saber, podem ser reinterpretados dentro das práticas de comunicação da sociedade atual? Este questionamento se baseia na relação entre os sistemas de formação das práticas discursivas e o surgimento do discurso. Esta relação é desenvolvida ao longo de $A$ arqueologia do saber e cotejada nas duas partes deste artigo. O aprofundamento da hipótese já referida contará com a contribuição intérpretes de Foucault com destaque 
ao autor contemporâneo ByungChul Han, filósofo de origem coreana radicado na Alemanha.

A primeira seção apresentará o propósito e o limite da arqueologia, referente ao livro de 1969, direcionando a leitura ao escopo da hipótese acima. A segunda seção procurará mostrar como os "sistemas de formação" podem constituir uma base para ação de sujeitos em pleno século XXI. Para alcançar este intento, algumas características dos "sistemas de formação" serão ressaltadas. Finalmente a conclusão deve tentar responder a condutora enunciada mais acima.

\section{As unidades discursivas e as po- sitividades}

Os objetivos de $A$ arqueologia do saber focam o discurso e o aprofundam para encontrar não somente as bases a partir das quais se pode investigar o discurso, mas, também, identificar os elementos concretos que estão associados. Estes elementos são denominados de "fatos do discurso" (FOUCAULT, 2008, p.29) ou "acontecimentos do discurso" (FOUCAULT, 2008, p.30). Estas expressões indicam objetos de estudos que não se resumem a um âmbito interno do discurso, mas sim estabelecem vínculos entre discurso e mundo concreto. Neste sentido a análise do discurso ocasiona uma série de problemas ao investigador, ou conforme Dreyfus e Rabinow, ao "arqueólogo". Uma das formas de apresentar os problemas referentes aos vínculos entre discurso e mundo concreto é através da interpretação da transição entre arqueologia e genealogia, ambas compreendidas como fases da reflexão de Foucault.

Algumas considerações podem ser feitas sobre os problemas que o "arqueólogo" encontra para lidar com o discurso sem perder a associação com os elementos concretos do mundo. Tais problemas podem ser mostrados por meio de diferentes abordagens: (a) sobre a possibilidade de um ponto de partida mais adequado à análise; (b) sobre os conceitos internos da própria arqueologia, em função dos quais o arqueólogo parece "estar ao mesmo tempo dentro e fora dos discursos que analisa, compartilhando o seu sentido, ao mesmo tempo em que os coloca entre parênteses" (DREYFUS; RABINOW, 2013, p.118). Esta abordagem (b) não será a principal deste artigo.

Sobre abordagem (a), Foucault afirma, especificamente no texto de A Arqueologia do saber, que duas alternativas não devem se constituir o ponto de partida da investigação do arqueólogo: a fe- 
nomenologia e a hermenêutica. Mas, é importante ressaltar que este livro de 1969, apresenta uma distinção fundamental com relação às rupturas entre as epistemes e a valorização das ciências como o "lugar específico da verdade" (MACHADO, 1982, p.184). Isto era realizado anteriormente na proposta de As palavras e as coisas de 1966. Agora, a Arqueologia do saber busca "articular o acontecimento discursivo com o acontecimento não discursivo, as formações discursivas com as formações não discursivas" (MACHADO, 1982, p.166). Por isto, através da exploração das descontinuidades históricas ela "privilegia em sua análise não mais a ciência, mas o saber" (MACHADO, 1982, p.184). Pois: "Ao nível do saber é possível estabelecer uma pluralidade de rupturas [...], uma incompatibilidade histórica entre discursos que entretanto conservam, cada um, sua positividade" (MACHADO, 1982, p.184-185). Resta descobrir porque um discurso acontece e o outro não. E, o ponto de partida não pode ser a fenomenologia e a hermenêutica, porque a compreensão de ambas, em suas variações contemporâneas, mostra "problemas metodológicos". $\mathrm{O}$ eixo desta abordagem carrega a necessidade de aproximar a análise do ser humano com análise do mundo vivo, perscrutar uma his- tória viva. Neste sentido, Foucault acompanha os desenvolvimentos iniciais das ciências humanas para se deter em como a análise do homem carece sempre de se suprir de uma base segura, de um fundamento, principalmente, após Descartes e após Kant. Mas, no século XIX, autores como Marx e Nietzsche se tornam referências de mudança: a entrada em um mundo histórico e vivo, vinculado a finitude. Entretanto, ambos os autores são reinterpretados: Marx é antropologizado e Nietzsche tem a sua concepção de método, a genealogia, distorcida. Vejamos:

Para tornar válido este tema que opõe à "imobilidade" das estruturas, a seu sistema "fechado", à sua necessária "sincronia", a abertura viva da história, é preciso, evidentemente, contestar nas próprias análises históricas o uso da descontinuidade, a definição dos níveis e dos limites, a descrição das séries específicas, a revelação de todo o jogo das diferenças. Somos, então, levados a antropologizar Marx, a fazer dele um historiador das totalidades e a reencontrar nele o propósito do humanismo; somos levados a interpretar 
Nietzsche nos termos da filosofia transcendental e a rebaixar sua genealogia no plano de uma pesquisa do originário; finalmente, somos levados a deixar de lado, como se jamais tivesse aflorado, todo este campo de problemas metodológicos que a história nova propõe hoje (FOUCAULT, 2008, p.15).

A busca de uma totalidade que sustente as análises sobre o homem provoca o uso inadequado dos dois autores mencionados que fizeram "a abertura viva da história”: uma inadequação sob a forma da antropologização e uma inadequação sob a forma da procura de uma origem ou de um pensamento profundo que estaria oculto. Estas inadequações refletem a busca de sustentação da concepção do homem como sujeito do conhecimento e do homem como objeto de estudo. Mas, a complexidade desta busca por totalidade, não pode prescindir da finitude. Esta problematização pode ser vista no seguinte comentário:

Antes daquela disposição, que é a moderna, o homem, como objeto de saber, não existia (renascen- tistas e clássicos); e diante da nova disposição dos saberes (época contemporânea) ele poderá desaparecer. Após o ocaso do infinito divino como fundamento da verdade na Representação clássica, torna-se empresa infrutífera erigir o homem finito como seu substituto. Ao contrário das filosofias modernas do sujeito, que elevam a finitude empírica do homem ao status de sujeito constituinte dos conhecimentos, a arqueologia de Michel Foucault apresenta-o constituído entre positividades; seu ser está rodeado por sua inexistência no passado e sua dispersão no porvir. Privilegia-se a arqueologia dos domínios empíricos da biologia, da filologia e da economia política para mostrar que o homem emerge pela primeira vez como objeto de conhecimento entre esses saberes empíricos, e não no lugar que normalmente se pensa, que é o da finitude no sentido filosófico (CANDIOTO, 2010, p.21). 
ter os instrumentos necessários para compreender o homem "constituído de positividades" e em uma "dispersão". Neste sentido, a arqueologia volta-se para diferentes "domínios empíricos" (biologia, filologia, economia política) que são "saberes". As funções enunciativas possuem condições que não são a fomentação do que vem a ser enunciado, vem a ser linguagem como "o súbito aparecimento de uma frase" (FOUCAULT, 2008, p.128). E, nem é uma liberdade prévia que permitisse "o labor do ser humano ou uma abertura transcendental" (FOUCAULT, 2008, p.128). As condições, que permitem que as funções enunciativas sejam efetuadas, podem ser descritas como positividades. A positividade é "o nível enunciativo", o que "está no limite da linguagem" (FOUCAULT, 2008, p.127). Este "nível enunciativo" possui suas peculiaridades: "Ele define a modalidade de seu aparecimento: antes sua periferia que sua organização interna, antes sua superfície que seu conteúdo" (FOUCAULT, 2008, p.127). E, finalmente: "Isso prova, também, que é inútil procurar, além das análises estruturais, formais, ou interpretativas da linguagem, um domínio finalmente liberto de qualquer positividade" (FOUCAULT, 2008, p.128). Esta positividade está nas funções enunciativas do século XXI e se torna parte do que permanece na transição para a temática do poder da arqueologia à genealogia. Veremos isto ao final desta seção.

A arqueologia deve dar conta da sua própria posição de análise, aquela que assume diante destes "saberes empíricos" e interpositividades ("entre positividades"). Esta posição e, o respectivo ponto de partida, deve ser diferente daqueles das inadequações antes referidas. A importância da escolha deste ponto de partida, adequado ao trabalho de análise nas ciências do homem, pode ser explicitada por um trecho de Dreyfus e Rabinow:

[...] Ao evitar a pesquisa da origem com sentido, a partir da qual o homem pudesse ter uma compreensão total e assim se apropriar novamente de sua positividade historicamente dispersa a partir de seu interior, o discurso arqueológico abandona a busca de uma origem que, ao produzir história, elide, constantemente, o estudo histórico, recuando em direção ao passado ou indo ao encontro do futuro. Como afirma Foucault, nas pri- 
meiras páginas de $A$ arqueologia do saber, o discurso arqueológico deve evitar as duas negativas paralelas da importância ontológica do discurso verdadeiro, que caracterizam as ciências do homem - aquela que pensa que a história é o trabalho das implicações de um mundo original que é sua origem inacessível, mas que não pode nunca ser explicitamente formulado, e a opinião correlata dos pensadores que afirmam haver uma realidade não linguística, seja o esclarecimento de práticas pré-linguísticas (como nos primeiros trabalhos de Heidegger), seja a percepção silenciosa (como em Merleau Ponty). Para o arqueólogo, não há sentido profundo, não há "origem escondida" na história ou fora dela, de modo que a tentativa hermenêutica de encontrar um fundamento anterior, por trás ou além da história, enquanto se situa na história, pode ser rejeitada como mais um imperativo humanístico inacabável. Uma vez que não tem sentido sério e não exige uma verdade séria, o discurso arqueólogo é anistórico. O arqueólogo descobriu um discurso que não é vida, cujo tempo não é o tempo da história e considera rigorosamente seus progressos, conflitos e declínio (DREYFUS; RABINOW, 2013, p.128).

O discurso do arqueólogo trata da história, mas não é um discurso histórico, (ele é "anistórico"). Este discurso do arqueólogo se mostra descolado do mundo: "um discurso que não é vida" e esta caracterização é um problema arqueologia. O problema resulta da preocupação com as unidades discursivas, o que é assim descrito pelos dois autores: “... estar ao mesmo tempo dentro e fora dos discursos que analisa, compartilhando seu sentido, ao mesmo tempo em que os coloca entre parênteses, é a condição inelutável do arqueólogo" (DREYFUS; RABINOW, 2013, p.118).

O foco da análise no discurso deve abranger tanto "os domínios empíricos" quanto uma história viva. Para dar conta desta complexa junção, Foucault elabora seus próprios conceitos sendo que um deles é o conceito de "estratégia" . Este será fio condutor nas análises que se seguem, Foucault o apresenta com as se- 
guintes palavras:

Discursos, como a economia, a medicina, a gramática, a ciência dos seres vivos, dão lugar a certas organizações de conceitos, a certos reagrupamentos de objetos, a certos tipos de enunciação, que formam, segundo seu grau de coerência, de rigor e de estabilidade, temas ou teorias: [...] Qualquer que seja seu nível formal, chamaremos, convencionalmente, de "estratégias" esses temas e essas teorias. O problema é saber como se distribuem na história (FOUCAULT, 2008, p.71).

Estas "estratégias" são compostas por "temas ou teorias" e se constituem de unidades de discursos que possuem um sistema de formação de regras. Os sistemas de formação serão tratados especificamente na próxima seção. Neste momento apenas destacamos que as unidades de discursos permitem uma organização específica "dos conceitos" e configuram graus de "rigor", de "coerência" etc. nas suas articulações enquanto discursos.

$\mathrm{Na}$ sequência da passagem citada mais acima Foucault apre- senta exemplos que mostram estas unidades de discurso configuradas em "temas" e "teorias", por exemplo, o tema da "língua originária” na gramática do século XVIII, a teoria do "parentesco entre todas as línguas" (FOUCAULT, 2008, p.71) no século XIX e a teoria econômica dos fisiocratas. Mas, nas unidades de discurso o importante não é uma discussão sobre as suas "contradições" internas, e sim porque elas podem "reivindicar um domínio" dentro da realidade e, de fato reivindicam, por meio de peculiares "acontecimentos discursivos". A peculiaridade destes acontecimentos remete ao modo de como estas unidades de discurso se relacionam com o tempo, o espaço e com as instituições. As palavras de Foucault são as seguintes:

E eu mesmo, de minha parte, nada farei senão isso: certamente tomarei por marco inicial unidades inteiramente formadas (como a Psicopatologia, ou a medicina, ou a economia política); mas não me colocarei no interior dessas unidades duvidosas para estudar-lhes a configuração interna ou as secretas contradições. Não me apoiarei nelas senão o tempo necessário 
para me perguntar que unidades formam; com que direito podem reivindicar um domínio que as especifique no espaço e uma continuidade que as individualize no tempo; segundo que leis elas se formam; sobre o pano de fundo de que acontecimentos discursivos elas se recortam; e se, finalmente, não são, em sua individualidade aceita e quase institucional, o efeito de superfície de unidades mais consistentes (FOUCAULT, 2008, p.29).

O foco é, então, o estudo dos problemas suscitados por estas unidades de discurso. Os problemas são expressos por meios das diversas perguntas que o autor apresenta. As perguntas mostram que o enfoque sobre as unidades de discurso não pode ser sustentado apenas por uma "quase evidência". Uma "quase evidência" que se explicitaria se as unidades de discurso fossem parte de um conhecimento que, em princípio, não precisaria ser esclarecido. A "quase evidência" se torna, portanto, um apelo a obviedade, fornecendo uma reação neutra frente à demanda de um aprofundamento da função exercida pela unidade de dis- curso. Função esta que extrapolaria o âmbito discursivo e atingiria o mundo concreto dos domínios empíricos. Neste sentido, Foucault apresenta as seguintes questões que devem ser colocadas às unidades de discurso:

Seria bem possível, por exemplo, que as noções de "influência" ou de "evolução" originassem uma crítica que as colocasse por um tempo mais ou menos longo - fora de uso. Mas a "obra", o "livro", ou ainda estas unidades como a "ciência" ou a "literatura", será preciso sempre dispensá-las? Será preciso tomá-las por ilusões, construções sem legitimidade, resultados mal alcançados? Será preciso desistir de se buscar qualquer apoio nelas, mesmo provisoriamente, e de lhes dar uma definição? Trata-se, de fato, de arrancá-las de sua quaseevidência, de liberar os problemas que colocam; reconhecer que não são o lugar tranqüilo a partir do qual outras questões podem ser levantadas (sobre sua estrutura, sua coerência, sua sistematicidade, suas transfor- 
mações), mas que colocam por si mesmas todo um feixe de questões (Que são? Como defini-las ou limitá-las? A que tipos distintos de leis podem obedecer? De que articulação são suscetíveis? A que subconjuntos podem dar lugar? Que fenômenos específicos fazem aparecer no campo do discurso?) (FOUCAULT, 2008, p.28-29).

Um ponto de apoio cumpre o papel de bastidor em toda exposição é a história. Ela é compreendida como "uma continuidade" que individualiza uma unidade de discurso. Mediante uma posição crítica frente à história, tomando-a como o plano em que se inserem as unidades de discurso, está a tarefa de encontrar o registro da continuidade por meio da análise dos acontecimentos discursivos. Estes acontecimentos, e os seus registros, pertencem ao mundo empírico. Isto significa que eles atingem ao mundo real das relações entre homens e instituições, explicando a tarefa da arqueologia apresentada claramente na introdução:

Denunciaremos um atentado contra os direitos im- prescritíveis da história e contra o fundamento de toda historicidade possível. Mas não devemos nos enganar: o que tanto se lamenta não é o desaparecimento da história, e sim a supressão desta forma de história que era em segredo, mas totalmente referida à atividade sintética do sujeito; o que se lamenta é o devir que deveria fornecer à soberania da consciência um abrigo mais seguro, menos exposto que os mitos, os sistemas de parentesco, as línguas, a sexualidade ou o desejo; o que se lamenta é a possibilidade de reanimar pelo projeto o trabalho do sentido ou o movimento da totalização, o jogo das determinações materiais, das regras de prática, dos sistemas inconscientes, das relações rigorosas mas não refletidas, das correlações que escapam a qualquer experiência vivida; o que se lamenta é o uso ideológico da história, pelo qual se tenta restituir ao homem tudo o que, há mais de um século, continua a lhe escapar (FOUCAULT, 2008, p.16). 
Entre os vários problemas enfrentados pela arqueologia está o do uso "ideológico" da história. Este problema pode ser considerado centralizador em comparação aos demais problemas: a supressão da "atividade sintética do sujeito", o "devir" e "a soberania da consciência" em um "abrigo mais seguro" e as "relações rigorosas, mas não refletidas", que escapam da "experiência vivida". Um possível uso não ideológico da história deveria, então, conduzir o processo de aprofundamento de cada um destes problemas e acompanhar as suas trajetórias.

Mas, percebe-se que todos os problemas antes mencionados atingem não somente a discussão da história e da sua continuidade. Eles, em geral, ampliam o âmbito das condições de ocorrência dos próprios acontecimentos discursivos. Esta ampliação desafia a proposta da arqueologia, pois a coloca sob a necessidade de ir além do discurso e de se aproximar mais dos domínios empíricos. Estes movimentos conduzem a própria arqueologia ao seu limite.

Uma síntese deste desafio representado pela condução para além dos acontecimentos discursivos pode ser compreendida nesta passagem: "[...] a análise meramente discursiva da arqueologia não responde por que alguns sa- beres vêm a se tornar ciências, porque certas positividades poderão ser qualificadas como disciplinas científicas e outras não?" (CANDIOTO, 2010, p.49). Uma resposta é afirmar que o desafio mesmo é impulsionador da passagem da arqueologia à genealogia. Tratar de assumir um outro centro: o poder. Assim, a partir da década de 70, a problemática do poder se torna o centro: "Essa é uma das razões que levou Foucault a introduzir a problemática do poder para entender como os saberes num determinado momento e numa cultura específica são reconhecidos como verdadeiros e como outros são desqualificados como falsos" (CANDIOTO, 2010, p.50). Esta necessidade de investigar porque algumas positividades são consideradas científicas e outras não, mostrou que era preciso ir além das unidades de discurso e da análise do discurso.

Aqui o tema das positividades retorna dentro de uma tensão entre a análise do discurso e o poder. As positividades mostram antes "a periferia que sua organização interna" e antes a "sua superfície que seu conteúdo" (FOUCAULT, 2008, p.128). Compreendidas como condições das funções enunciativas, as positividades conduzem a uma discussão sobre o poder. Esta discussão revela elementos que estão aquém 
e além do discurso. Justamente, porque as positividades tratam da "periferia" e da "superfície" e não prioritariamente do "conteúdo". Mas, neste novo âmbito, o poder se mostra ambíguo: ele se exerce pelo discurso, na afirmação de direitos aos indivíduos. $E$, ele se exerce enquanto biopoder: mediante as "disciplinas, uma anátomo-política do corpo humano" (CASTRO, 2016, p.57) e, como "uma biopolítica da população, do corpo espécie" (CASTRO, 2016, p.58). Mas, ainda assim, as funções enunciativas atuais em suas respectivas positividades (tornadas agora mais complexas), possuem a possibilidade de um aprofundamento, seja a respeito das estratégias que incluem os sistemas de formação das práticas discursivas, seja sobre o biopoder. Este último expresso conforme a época, no século XXI, por meio da tecnologia digital.

Esta seção procurou mostrar as principais características da arqueologia em Foucault, estabelecendo não somente uma explicitação de seus propósitos, mas também o seu limite. Os propósitos se vinculam ao estudo da continuidade das unidades de discursos nos diferentes saberes dentro do tempo, isto é, na história. E, o limite da arqueologia se encontra na distinção entre disciplinas, resultando em uma valoriza- ção histórica diferenciada, explicar esta diferenciação se torna um problema. A conclusão parcial é: o limite depende da explicitação de fatores para além dos conteúdos do discurso (positividades) e que, por causa disto, alcançam o tema do poder. Na segunda seção vamos explorar os sistemas de formação de regras das práticas discursivas, ou seja, dentro do escopo da arqueologia, para encontrar recursos a uma análise da época atual.

\section{Os sistemas de formação das prá- ticas discursivas e a época atual}

Esta seção investigará quais os recursos da arqueologia que podem ser utilizados para uma análise dos cenários atuais, abordando os "domínios empíricos" das relações de poder. O texto da Arqueologia do saber possui centralidade no discurso e nas unidades de conhecimentos, mas isto não impede um enfoque nas instâncias singulares dos sujeitos falantes e suas vidas na sociedade. Para tanto, será necessário nos apoiarmos em alguns conceitos já mencionados na seção anterior, mais especificadamente no conceito de estratégia e no conceito de "sistema de formação de regras". O primeiro é caracterizado por possuir temas e teorias dentro de uma coerência 
interna às unidades de discurso; o segundo deverá estabelecer um vínculo entre o texto da Arqueologia do saber e a época atual.

Inicialmente, retomemos o propósito da arqueologia e o seu mote: na primeira seção vimos que o mote é a história. Ele funciona com um pano de fundo, no qual se destaca o tema do "discurso". Tal destaque pode ser percebido no uso freqüente das expressões: "unidades de discurso", "enunciação", "temas" e "teorias". Mas, o foco no discurso possui certos parâmetros: não se deve fazer uma análise do discurso a partir da subjetividade, a qual Foucault denomina "pensamento". É preciso ampliar o foco até os "domínios empíricos" e verificar o porquê da enunciação acontecer ou não, ou seja, verificar as exclusões:

A análise do pensamento é sempre alegórica em relação ao discurso que utiliza. Sua questão, infalivelmente, é: o que se dizia no que estava dito? A análise do campo discursivo é orientada de forma inteiramente diferente; trata-se de compreender o enunciado na estreiteza e singularidade de sua situação; de determinar as condições de sua existên- cia, de fixar seus limites da forma mais justa, de estabelecer suas correlações com os outros enunciados a que pode estar ligado, de mostrar que outras formas de enunciação exclui. Não se busca, sob o que está manifesto, a conversa semi-silenciosa de um outro discurso: deve-se mostrar por que não poderia ser outro, como exclui qualquer outro, como ocupa, no meio dos outros e relacionado a eles, um lugar que nenhum outro poderia ocupar. A questão pertinente a uma tal análise poderia ser assim formulada: que singular existência é esta que vem à tona no que se diz e em nenhuma outra parte? (FOUCAULT, 2008, p.31)

Conforme a passagem acima, o discurso pode ser transpassado em função de: (a) uma "análise do pensamento" ou (b) uma "análise do campo discursivo". Em relação a última, ela é "orientada de forma inteiramente diferente" e Foucault faz uma crítica da busca da "conversa silenciosa de um outro discurso". Ele procura singularizar a situação e expor a estratégia da unidade de discurso quando ocorre uma enunciação. A 
estratégia nem sempre está manifesta na enunciação. Mas, a estratégia compõe as "condições de sua existência", dos "limites", das correlações e das exclusões. Portanto, ela implica uma história e uma concretude viva do mundo. A exposição mais detalhada das estratégias se torna a tarefa mais importante, inclusive no propósito de aproximar o texto da Arqueologia do saber com a nossa época atual.

As estratégias são uma forma de nomear um conjunto de temas e teorias. Assim, para que a estratégia seja identificada é preciso que ocorra uma "regularidade". Esta regularidade aponta na direção dos "sistemas de formação". A respeito disso, no primeiro item do primeiro capítulo (item denominado de "As unidades do discurso"), Foucault assinala qual seria a atitude mais pertinente do investigador frente a tais "regularidades". Elas são compreendidas como "continuidade do discurso":

É preciso renunciar a todos esses temas que têm por função garantir a infinita continuidade do discurso e sua secreta presença no jogo de uma ausência sempre reconduzida. É preciso estar pronto para acolher cada momento do discurso em sua irrupção de acontecimentos, nessa pontualidade em que aparece e nessa dispersão temporal que lhe permite ser repetido, sabido, esquecido, transformado, apagado até nos menores traços, escondido bem longe de todos os olhares, na poeira dos livros. Não é preciso remeter o discurso à longínqua presença da origem; é preciso tratá-lo no jogo de sua instância. Essas formas prévias de continuidade, todas essas sínteses que não problematizamos e que deixamos valer de pleno direito, é preciso, pois, mantê-las em suspenso. Não se trata, é claro, de recusá-las definitivamente, mas sacudir a quietude com a qual as aceitamos; mostrar que elas não se justificam por si mesmas, que são sempre o efeito de uma construção cujas regras devem ser conhecidas e cujas justificativas devem ser controladas; definir em que condições e em vista de que análises algumas são legítimas; indicar as que, de qualquer forma, não podem mais ser admitidas 
(FOUCAULT, 2008, p.29).

Estas indicações do trabalho do arqueólogo a respeito da "análise do campo discursivo" visam circunscrever um determinado discurso e esclarecer qual seria "estratégia", vinculado ao mesmo. O deixar "em suspenso" das "formas prévias de continuidade", abre a possibilidade de aprofundamento sobre a concatenação interna das teorias e dos temas nos processos de aceitação ou de exclusão constantes no mundo histórico, ou seja, acontecem diversas relações entre homens e instituições. Por isto, as concatenações dos diferentes discursos em suas unidades são acompanhadas pelo arqueólogo dentro dos "domínios empíricos". Isto exige, por si só, uma ultrapassagem do meramente dito ou do meramente enunciado na direção do âmbito dos "fatos do discurso". E, este acesso aos "fatos do discurso" significa compreender uma determinada estratégia. É preciso estar atento à "regularidade" existente no "campo discursivo". É preciso buscar definir o seu "sistema de formação" e, somente este conjunto de procedimentos ou de precauções, permitirá uma resposta aos seguintes questionamentos:

Será por um determi- nismo que as encadeia, as torna inevitáveis, as chama exatamente a seu lugar, umas após outras, e, de fato, como as soluções sucessivas de um único e mesmo problema? Ou por encontros aleatórios entre idéias de origem diversa, influências, descobertas, climas especulativos, modelos teóricos que a paciência ou o gênio dos indivíduos disporia em conjuntos mais ou menos bem constituídos? A menos que seja possível encontrar entre elas uma regularidade e que sejamos capazes de definir o sistema comum de sua formação (Foucault, 2008, p.71-72).

A suspensão das "formas prévias de continuidade" requer o aprofundamento exposto pelo conceito de estratégia. Este conceito se vincula ainda com outros conceitos como o de "formação discursiva" e, por sua vez, este remete a um "sistema de formação": "Uma formação discursiva será individualizada se puder definir o sistema de formação das diferentes estratégias que nela se desenrolam" (FOUCAULT, 2008, p.76).

A caracterização precisa do sistema de formação implica uma dinâmica que o insere em um jogo 
de relações. Este jogo de relações é efetivado no mundo histórico e possui cenários específicos diversos. Há uma tensão que afasta a consideração meramente lingüística. Neste sentido, a possibilidade mesma de aproximar a proposta de Foucault com os tempos atuais, precisa reter um elemento dinâmico. Este elemento dinâmico pode ser representado pelo conceito de "sistema de formação". Pois, quando se esclarece este conceito, verificamos esta potencialidade. Foucault prepara o caminho de um esclarecimento deste conceito, indicando as respectivas características:

Esses sistemas de formação não devem ser tomados como blocos de imobilidade, formas estáticas que se imporiam do exterior ao discurso e definiriam, de uma vez por todas, seus caracteres e possibilidades. Não são coações que teriam sua origem nos pensamentos dos homens, ou no jogo de suas representações; mas não são, tampouco, determinações que, formadas no nível das instituições ou das relações sociais ou da economia, viriam transcrever-se, à força, na superfície dos discursos.
Esses sistemas - já insistimos nisso - residem no próprio discurso; ou antes (já que não se trata de sua interioridade e do que ela pode conter, mas de sua existência específica e de suas condições) em suas fronteiras, nesse limite em que se definem as regras específicas que fazem com que exista como tal. Por sistema de formação é preciso, pois, compreender um feixe complexo de relações que funcionam como regra: ele prescreve o que deve ser correlacionado em uma prática discursiva, para que esta se refira a tal ou tal objeto, para que empregue tal ou tal enunciação, para que utilize tal ou tal conceito, para que organize tal ou tal estratégia. Definir em sua individualidade singular um sistema de formação é, assim, caracterizar um discurso ou um grupo de enunciados pela regularidade de uma prática (FOUCAULT, 2008, p.82-83).

Uma adaptação aos tempos atuais pode assumir as posições mais recentes frente ao trabalho crítico de Foucault. Neste sentido, não é 
razoável ignorar o passo dado pela posição de Deleuze, considerando a passagem da sociedade disciplinar a uma sociedade de controle (DELEUZE, 2013, p.224). Entretanto, é possível ir além, incluindo a análise mais recente dos softwares preditivos de "aprendizado de máquina” (MACKENZIE, 2017). No entanto, todos estes aportes adquirem uma articulação possível com a interpretação de ByungChul Han, filosofo sul-coreano radicado na Alemanha.

Referindo-se a Foucault, Han faz o seguinte diagnóstico: "A sociedade disciplinar de Foucault, feita de hospitais, asilos, presídios, quartéis e fábricas, não é mais a sociedade de hoje. [...]. A sociedade do século XXI não é mais a sociedade disciplinar, mas uma sociedade de desempenho" (HAN, 2017a, p.23). Na sociedade de desempenho se modificaram as relações de poder e cada indivíduo assumiu para si a tarefa dinâmica de uma autoexploração. Esta autoexploração combina com o capitalismo tardio pós-industrial, pois mantém o indivíduo em uma azáfama:

O sujeito de desempenho está livre da instância de domínio exterior que o obrigue ao trabalho e o explore. Está submetido apenas a si pró- prio. Mas a suspensão da instância de domínio externa não elimina a estrutura de coação. Ela, antes, unifica liberdade e coação. O sujeito de desempenho acaba entregandose à coação livre a fim de maximizar seu desempenho. Assim ele explora a si mesmo. Ele é o explorador e ao mesmo tempo o explorado, o algoz e a vítima, o senhor e o escravo. O sistema capitalista mudou o registro da exploração estranha para a exploração própria, a fim de acelerar o processo (HAN, 2017a, p.105).

A unificação entre "liberdade e coação" gera a possibilidade de uma "coação livre", a qual acontece no sujeito consigo mesmo. Hoje, em plena sociedade de desempenho, as práticas discursivas manifestam os diferentes modos desta "coação livre" como autoexploração. Nas práticas discursivas atuais, um estudo das manifestações discursivas deve levar em conta os efeitos da mídia em redes. E, dentro deste contexto, não é suficiente partir do ponto de que a sociedade seja do tipo " disciplinar" ou, ainda, de "controle". Embora, ambas as formas ainda existam: a disciplina 
converge para a autodisciplina e o controle converge para uma forma não explícita (vejam-se os exemplos recentes de espionagem e coleta de dados ou de padrões para a orientação do comportamento eleitoral de políticos). Diante disto, as práticas discursivas atuais são redefinidas em um mundo perpassado pela comunicação digital. E, consequentemente, as práticas discursivas repousariam sobre um sistema de formação de regras amplamente flexível e maleável. Neste último aspecto, reencontramos esta flexibilidade e maleabilidade em alguns aspectos centrais do o texto da Arqueologia do saber tal como será demonstrado a seguir.

Ao tratar das "escolhas teóricas", dentro da explicação dos "sistemas de formação" , Foucault menciona "um campo de práticas não discursivas", ao qual chega abordar no ponto em que ele denomina as "posições possiveis do desejo em relação ao discurso" (FOUCAULT, 2008, p.75, itálicos do autor). Estas "posições possíveis" abrem a alternativa de aproximar o "sistema de formação", mencionado em uma passagem anterior, com as práticas discursivas. Neste caso, "as práticas discursivas" podem ser compreendidas como similares as ações do sujeito narcisista do século XXI. Tal suposição se torna plau- sível assim:

Finalmente, essa instância se caracteriza pelas posições possiveis do desejo em relação do discurso: este, na verdade, pode ser o local de uma encenação fantasmática, elemento de simbolização, forma do proibido, instrumento de satisfação derivada (essa possibilidade de estar relacionado com o desejo não é apenas o fato do exercício poético, romanesco ou imaginário do discurso: os discursos sobre a riqueza, linguagem, natureza, loucura, vida e morte, e muitos outros talvez, que são muito mais abstratos, podem ocupar, em relação ao desejo, relações bem determinadas). De qualquer modo, a análise dessa instância deve mostrar que nem a relação do discurso com o desejo, nem os processos de sua apropriação, nem seu papel entre as práticas não discursivas são extrínsecos à sua unidade, à sua caracterização, e às leis de sua formação. Não são elementos perturbadores que, superpondo-se à sua forma pura, neutra, in- 
temporal e silenciosa, a reprimiriam e fariam falar em seu lugar um discurso mascarado, mas sim elementos formadores (FOUCAULT, 2008, p.75, itálicos do autor).

Os vários tipos de discurso, sobre a "riqueza, linguagem, natureza, loucura, vida e morte e muitos outros" assinalam uma "relação do discurso com o desejo". Esta relação faz parte dos "elementos formadores" , não propriamente de uma repressão ou de uma usurpação mediante o uso de um "discurso mascarado" . Mas, existem ligações entre os elementos perturbadores, compondo um "sistema de formação" das práticas discursivas. Hoje o sujeito está imerso nas redes digitais de comunicação e, por isto, os "sistemas de formação" das práticas discursivas e das unidades de discurso devem se apresentar mais flexíveis. Pois, elas incorporam inúmeros elementos heterogêneos, por exemplo, podemos seguir na aproximação:

Vimos que - e, sem dúvida, não há necessidade de voltarmos ao assunto -, quando se fala de um sistema de formação, não se compreende somente a justaposição, a coexistência ou a interação de elementos heterogêneos (instituições, técnicas, grupos sociais, organizações perceptivas, relações entre discursos diversos), mas seu relacionamento - sob uma forma bem determinada - estabelecido pela prática discursiva (FOUCAULT, 2008, p.80-81).

Alguns elementos heterogêneos podem ser antevistos, também, na análise de Byung-Chul Han sobre a sociedade atual. A interpretação deste visa o indivíduo integrante de uma sociedade pós-disciplinar e de controle não explícito ou controle virtual. Entretanto, igualmente como Foucault, a base geradora das práticas discursivas está voltada aos domínios empíricos.

Han cria o conceito de "sociedade do desempenho" e, neste sentido, o sistema de formação das práticas discursivas se vincula às demandas individuais dentro de uma "sociedade de desempenho". Este tipo de sociedade delega as tarefas da disciplina, e do controle, ao próprio indivíduo, colocando em destaque uma exploração, ou melhor, autoexploração. Na sociedade do desempenho, a coação é encontrada sob a forma paradoxal de uma "coação livre", o que signi- 
fica que cada indivíduo deve administrar a si mesmo, carregando consigo o seu próprio campo de trabalho.

Em uma outra obra de $2012^{1}$, cujo título é Sociedade da transparência, Han retoma o tema do panóptico. Nesta retomada, as práticas dos indivíduos são balizadas em uma flexibilidade ampla. A flexibilidade pode ser compreendida como um efeito propiciado pelos sistemas digitais de informação. As novas diretrizes do panóptipo são as de que cada um possui a tarefa de mostrar as suas competências, administrar os seus perfis, e se responsabilizar por ser "produtivo".

Estas diretrizes rompem a barreira da disciplina, porque prescindem de uma ordem ou de comando externos. Elas rompem a barreira do controle explícito, porque o exercício da vigilância através da coleta e análise dos dados é demasiadamente complexo e é necessário um conhecimento técnico empreendê-lo (ASSANGE et al. 2013, ASSANGE, 2015). Estes elementos transformam a concepção panóptico exposta na genealogia do poder de Vigiar e punir em um novo panóptico "digital", assim apresentado:
[...] no momento, não vivemos o final do panóptico, mas o começo de um novo tipo de panóptico: aperspectivístico. O panóptico digital do século XXI é aperspectivístico na medida em que não é mais vigiado por um centro, não é mais supervisionado pela onipotência do olhar despótico. A distinção entre centro e periferia, essencial para o panóptico de Bentham, desapareceu totalmente. O panóptico digital surge agora totalmente desprovido de qualquer ótica perspectivística, e isso é que constitui seu fator de eficiência. A permeabilidade transparente aperspectivística é muito mais eficiente do que supervisão perspectivística, visto que é possível ser iluminado e tornado transparente a partir de todos os lugares, por cada um (HAN, 2017b, p.105-106, itálicos do autor).

Se compreendermos o "sistema de formação" das práticas discursivas como integrado em uma

${ }^{1}$ Publicado em alemão em 2012: Transparenzgesellschaft, e traduzido para o português em 2017 (Sociedade da transparência), indicado no texto, a partir de agora, com a data $2017 \mathrm{~b}$. 
"sociedade do desempenho", então o esforço desenvolvido pela arqueologia é estendido até os seus limites. Isto representaria uma intensificação dos "sistemas de formação" de forma a abranger, também, as práticas discursivas na era digital (ou na era do "panóptico digital" ). Com esta intensificação, a arqueologia poderia ser abordada no que diz respeito, especificamente, aos "sistemas de dispersão", constantes no texto da obra (FOUCAULT, 2008, p.43). Os "sistemas de dispersão" são destacados, inclusive, por H. Dreyfus e P. Rabinow. Primeiramente, eles mostram o confronto dos "sistemas de dispersão" com a análise mais convencional baseada no "pensamento" e na subjetividade:

[...] Na arqueologia, essa recuperação do impensado pelo pensamento se transforma na recuperação de um sistema não consciente de regras por uma teoria explícita. Assim, não são mais as condições das formas e dos conteúdos da consciência, mas das formas e dos conteúdos do discurso sério que são buscadas. Porém, a estrutura é a mesma: as "totalidades significantes" foram sim- plesmente substituídas pelos "sistemas de dispersão" e as regras transcendentais pelas regras de transformação (DREYFUS; RABINOW, 2013, p.126).

A crítica das "regras transcendentais" e o destaque das "regras de transformação" mostram as mudanças no processo de compreensão das condições das ocorrências de práticas discursivas. Elas não são "condições de possibilidade", ou seja, não são transcendentais, mas, são analisadas como "condições de ocorrência". Valoriza-se a efetividade contida nas ocorrências descritas ora como "acontecimentos discursivos", ora como "fatos do discurso" (termos foucaultianos). O importante é perguntar sobre estas "condições de " ocorrências na época atual. Uma interpretação que abre esta possibilidade é que:

[...] As práticas discursivas sérias, conforme vimos, são apresentadas como a condição de sua própria ocorrência. Conjuntos de práticas discursivas aparecem para revelar certas regularidades. Obviamente, as regras que 
descrevem estas regularidades não se apresentam como condições de possibilidade desses conjuntos, já que essas regras não definem o espaço total no qual todos os atos discursivos sérios poderiam ocorrer. Elas são, assim, claramente diferenciadas das regras transcendentais de Kant e dos filósofos críticos. Porém, são apresentadas como condições de ocorrência dos enunciados, de modo que, uma vez que o arqueólogo define regras que descrevem uma formação discursiva, particular, ele descobre que os atos discursivos efetivamente produzidos e considerados sérios são os únicos que a época permitia (DREYFUS; RABINOW, 2013, p.124).

A compreensão das regras descritoras de uma "regularidade" desloca a possibilidade de que as suas condições sejam condições de possibilidade e, se tornem "condições de ocorrência". Isto se deve porque as regras "não definem o espaço total" da ocorrência dos "atos discursivos". E, os "acontecimentos discursivos" ou "fatos do discurso" se manifestam nas "práticas discursivas sérias" que possuem as condições de "sua própria ocorrência". Cabe ao arqueólogo definir estas regras em compatibilidade com as a respectiva época que ele está analisando, para, assim, conseguir alcançar as condições em "sua própria ocorrência".

$\mathrm{Na}$ época em que vivemos, no fluxo digital de informações, a compreensão dos sistemas de formação, sob a forma de "sistemas de dispersão", faz com que as regras não tenham um sentido definido. Por isto, o sistema de formação é esvaziado de uma possível ingenuidade que lhe requisitaria um sentido. Inusitadamente, o não ter sentido se torna o modo mais adequado para estabelecer um sistema de autoexploração. E, também, inclui o tema das motivações das "convicções dos sujeitos falantes". Uma complexa articulação destas convicções e as práticas discursivas, compatível com a era digital, pode ser encontrada neste comentário de Dreyfus e Rabinow:

[...] o impensado dos sujeitos falantes é recuperado na teoria da arqueologia que, como análise do fenomenólogo sobre a tese da atitude natural, termina por negar a inteligibilidade da tese que tenta explicar. As práticas dis- 
cursivas, analisadas pelo arqueólogo, são motivadas pela convicção dos sujeitos falantes de que ajudam a explicitar os pensamentos implícitos daqueles que possuem tais verdades. A análise, contudo, substitui essa convicção "ingênua" por um conjunto de regras sem sentido como sua condição de ocorrência (DREYFUS; RABINOW, 2013, p.125).

Os "sujeitos falantes" da era digital estão comprometidos com as condições de ocorrência e com as regras (sem um sentido definido previamente) das suas respectivas práticas. Isto faz com que o sistema de formação, ao qual estão submetidos, seja flexível e de difícil compreensão por parte destes mesmos sujeitos. A intensa comunicação entre os sujeitos falantes (ou habitantes digitais) faz com que panóptico do século XXI não privilegie o isolamento, mas sim a transparência e a exposição pessoal. Tal exposição integra, enquanto conteúdo importante, as práticas discursivas. Han descreve este novo panóptico da seguinte forma:

A sociedade do controle atual apresenta uma es- trutura panóptica bastante específica. Contrariamente à população carcerária, que não tem comunicação mútua, os habitantes digitais estão ligados em rede e têm uma intensiva comunicação entre si. O que assegura a transparência não é o isolamento, mas a hipercomunicação. A especificidade do panóptico digital é sobretudo o fato de que seus freqüentadores colaboram ativamente e de forma pessoal em sua edificação e manutenção, expondo-se e desnudando-se a si mesmos, expondo-se ao mercado panóptico. O expor pornográfico e controle panóptico misturam-se entre si; o que alimenta o exibicionismo e o voyeurismo é a rede enquanto panóptico digital. Nesse sentido, a sociedade de controle chega a sua consumação ali onde o sujeito dessa sociedade não se desnuda por coerção externa, mas a partir de uma necessidade gerada por si mesmo; onde, portanto, o medo de renunciar à sua esfera privada e íntima dá lugar à ne- 
cessidade de seu expor à vista sem qualquer pudor (HAN, 2017b, p.108-109).

A interpretação acima da sociedade atual pode ser dividida em dois elementos principais: uma descrição do sujeito na sociedade de desempenho, o qual realizaria as referidas práticas discursivas. Nela se enquadrariam as motivações da "convicção dos sujeitos falantes" (DREYFUS; RABINOW, 2013, p.125); e (b) uma síntese dos aspectos principais da própria sociedade de desempenho. Sobre (a) e (b) podemos explicitar as suas características nas duas passagens abaixo de ByungChul Han.

Primeiramente sobre os sujeitos falantes atuais (a):

O sujeito de desempenho da modernidade tardia não se submete a nenhum trabalho compulsório. Suas máximas não são obediência, lei e cumprimento do dever, mas liberdade e boa vontade. Do trabalho, espera acima de tudo alcançar prazer. Tampouco se trata de seguir o chamado de um outro. Ao contrário, ele ouve a si mesmo. Assim, ele se desvincula da negativi- dade das ordens do outro. Mas essa liberdade do outro não só lhe proporciona emancipação e libertação. A dialética misteriosa da liberdade transforma essa liberdade em novas coações (HAN, 2017a, p.83).

Em segundo lugar, sobre a própria sociedade de desempenho (b). Um trecho que favorece uma transposição do conceito de sistema de formação das práticas discursivas:

$\mathrm{Na}$ sociedade do trabalho e do desempenho de hoje, que apresenta traços de uma sociedade coativa, cada um carrega consigo um campo, um campo de trabalho. A característica específica desse campo de trabalho é que cada um é ao mesmo tempo detento e guarda, vítima e algoz, senhor e escravo. Nós exploramos anos mesmos. $\mathrm{O}$ que explora é ao mesmo tempo o explorado. Já não se pode distinguir entre algoz e vítima. Nós nos otimizamos rumo à morte, para melhor poder funcionar. Funcionar melhor é interpretado fatalmente como melhoramento do si-mesmo (HAN, 2017a, 


\section{p.115).}

As diretrizes da sociedade do desempenho (simultaneamente: guarda e algoz, explorador e explorado, melhoramento de si mesmo etc.) combinam com as práticas dos sujeitos falantes - ou digitadores (por causa do uso dos dedos nos celulares). Combinam com a prática de não se submeter a trabalho compulsório, de ouvir somente a si mesmo, desvincularse da negatividade etc. Assim, os sistemas de formação de regras, encontram uma forma intensificada, pois eles se tornam sistemas de dispersões que constituem o cenário de fundo às manifestações das convicções das singularidades individuais destes "habitantes digitais". Todos integrando o novo panóptico aperspectivístico. Esta nova forma de panóptico faz com que surja um novo paradigma na análise do poder conforme estas palavras de Han:

Hoje uma nova mudança de paradigma se realiza. O panóptico digital não é uma sociedade disciplinar biopolítica, mas sim uma sociedade da transparência psicopolítica. E, no lugar do biopoder, entra o psicopoder. A psico- política está em posição para, com ajuda da vigilância digital, ler e controlar pensamentos. A vigilância digital toma o lugar da ótica inconfiável, ineficiente e perspectivista do Big Brother. Ela é eficiente porque ela é aperspectivista. A biopolítica não permite nenhum acesso sutil à psyche de pessoas. O psicopoder, em contrapartida, está em condições de intervir nos processos psicológicos (HAN, 2018, p.130-131).

O "psicopoder" faz a efetividade do poder alcance, também, a psique dos sujeitos, pois por meios de coleta de datas e modelagem, como aquela que é feita pelos softwares de machine learning, consegue, em alguma medida, "ler e controlar pensamentos". Entretanto, a troca de informações digitais entre os sujeitos falantes, ou "habitantes digitais", representa ainda uma forma de realização das "práticas discursivas".

Esta aproximação entre Foucault e Han, no que diz respeito à Arqueologia do saber, tem aqui um ponto favorável. O aprofundamento de ainda outros pontos possíveis necessitaria de ulteriores desenvolvimentos que ultrapassariam as dimensões de um só 
artigo.

Esta segunda seção procurou mostrar uma aproximação entre os sistemas de formação de regras e alguns aspectos da dinâmica da sociedade atual. Esta aproximação pode ser compreendida como um sistema de formação de regras discursivas intensificado. A sua caracterização apresenta as determinações pertinentes a uma sociedade de desempenho, o que significa ir além de uma concepção de sociedade disciplinar e de uma sociedade de controle (explícito).

\section{Considerações finais}

Esta análise do texto da Arqueologia do saber abordou na primeira seção os propósitos e limites deste livro e a segunda seção procurou aprofundar o conceito de sistema de formação das práticas discursivas. Estas duas seções procuraram uma resposta para o questionamento principal, o qual perguntava se os sistemas de formação das práticas discursivas, mencionados na Arqueologia do saber, poderiam ser reinterpretados dentro das práticas de comunicação da sociedade atual. A hipótese, que cada uma das duas seções procurou sustentar foi a de que o texto da Arqueologia do saber pode sim ser reinterpretado e. além disso, contribui com recur- sos teóricos para a interpretação da realidade atual.

A conclusão da primeira seção mostrou os seguintes resultados: a arqueologia possui o propósito de estudar a continuidade nas unidades de discursos, nos diferentes saberes dentro do tempo, tendo como pano de fundo a história. Neste caso, a história não é compreendida como historiografia, mas como história viva ou concreta. O limite da arqueologia encontra-se na dificuldade de explicar a distinção entre as disciplinas num plano histórico, por que o privilégio de algumas e exclusão de outras? Finalmente, a primeira seção sugere que a explicitação do limite aponta para o tema do poder, isto é, não apenas para dentro do âmbito das unidades do discurso.

A segunda seção realizou uma análise com o objetivo de aproximar o texto da Arqueologia do saber com época atual. A época atual foi caracterizada como dinâmica e flexível, em que os sujeitos falantes são integrantes de mundo de comunicação digital. A aproximação da arqueologia, com o século XXI, foi realizada por meio do conceito de "sistema de formação" das regras discursivas. E a conclusão desta seção é a de que o "sistema de formação de regras" pode ser o ponto de aproximação desde que ele assuma uma forma 
intensificada. Esta forma intensificada foi identificada quando o "sistema de formação" favorece a sua característica de ser um "sistema de dispersão".

Finalmente, a resposta para ao nosso questionamento principal é que a Arqueologia do saber pode contribuir para uma interpretação da realidade e da sociedade atual por meio do conceito de "sistema de formação" das práticas discursivas, desde que este sistema seja compreendido de forma intensificada. Esta resposta aponta para a necessidade de retomar ainda outros conceitos de Foucault para dar conta de uma fugidia realidade construída pela tecnologia no mundo atual.

\section{Referências}

ASSANGE, J et al. Cypherpunks: liberdade e o futuro da internet. Tradutora: Cristina Yamagami. $1^{\text {a }}$ edição, São Paulo, Boitempo, 2013. . 2014 - Quando o Google encontrou o Wikileaks. Tradutora: Cristina Yamagami. $1^{a}$ edição, São Paulo, Boitempo, 2015.

CANDIOTO, C. Foucault e a crítica da verdade. $1^{\text {a }}$ edição, Belo Horizonte e Curitiba, Editora Autêntica e Champagnat, 2010.

CASTRO, E. Vocabulário de Foucault: um percurso pelos seus temas, conceitos e autores. Tradutora: Ingrid Müller Xavier. $2^{\mathrm{a}}$ edição. Belo Horizonte, Autêntica Editora, 2016.

DELEUZE, G. Conversações (1972-1990). Tradutor: Peter Pál Pelbart. $3^{a}$ edição, São Paulo, Editora 34, 2013.

DREYFUS, H.; RABINOW, P. Michel Foucault: uma trajetória filosófica, para além do estruturalismo e da hermenêutica. Tradutores Vera Porto Carrero e Gilda Gomes Carneiro; introdução: traduzida por Antonio Cavalcanti, $2^{a}$ edição. Rio de Janeiro, Forense Universitária, 2013.

FOUCAULT, M. A arqueologia do saber. Tradutor: Luiz Felipe Baeta Neves, $7^{\text {a }}$ edição, Rio de Janeiro, Forense Universitária, 2008.

HAN, B-C. Sociedade do cansaço. Tradutor: Enio Paulo Giachini, $2^{\mathrm{a}}$ edição, Petrópolis: Vozes, 2017a.

- Sociedade da transparência. Tradutor: Enio Paulo Giachini, $1^{\text {a }}$ edição, Petrópolis, Vozes, 2017b.

. No enxame: perspectivas do digital. Tradutor: Lucas Machado. $1^{\mathrm{a}}$ edição, Petrópolis: Vozes, 2018. 
MACKENZIE, A. Machine learners: archaeology of a data practice. $1^{\mathrm{a}} \mathrm{ed} .$, Cambridge, MIT Press, 2017.

MACHADO, R. Ciência e saber: a trajetória da arqueologia de Foucault. $1^{\mathrm{a}}$ ed. Rio de Janeiro, Edições Graal, 1982.

Recebido: $20 / 02 / 2019$

Aprovado: 03/05/2019

Publicado: 13/05/2019 